\title{
Effect of Essential Oil and Aqueous Extract of Ginger (Zingiber Officinale) on Oxidative Stability of Fish oil-in-Water Emulsion
}

\author{
Jeya Kumari ${ }^{1 *}$, Venkateshwarlu $\mathbf{G}^{2}$, Choukse $\mathbf{M K}^{\mathbf{2}}$ and Anandan $\mathbf{R}^{1}$ \\ ${ }^{1}$ Central Institute of Fisheries Technology, Cochin-682029, Kerala, India \\ ${ }^{2}$ Central Institute of Fisheries Education, Versova, Mumbai-400061, Maharashtra, India
}

\begin{abstract}
Fish oil-in-water emulsion (5\%) was prepared with essential oil and aqueous extract of ginger (Zingiber officinale) rhizome and their oxidative stability was examined. Antioxidant activities of essential oil and aqueous extract of ginger revealed total phenolic was high in essential oil ( $130.70 \mathrm{mg}$ Catechol equivalents /I) than aqueous extract ( $24.38 \mathrm{mg}$ Catechol equivalents /I) at $5 \%$ concentration. Chemical composition of Ginger (Zingiber officinale) essential oil was determined by GC-MS analyses showed Ginger essential oil contained, zingiberene $(27.45 \pm 0.30 \%)$, copaene $(13.82 \pm 0.06 \%)$, camphane $(11.10 \pm 0.16 \%)$, geranial $(10.98 \pm 0.10)$, as the major compounds. Oxidative stability test (thiobarbituric acid reactive substances) revealed that, In oil-inwater emulsion, essential oil $(1 \%)$ and aqueous extract $(20 \%)$ together acted more significantly $(p<0.05)$ against lipid oxidation $\left(9.21 \mathrm{~m} \mathrm{~mol} \mathrm{O}_{2} / \mathrm{kg}\right.$ and $3.02 \mathrm{mg}$ malonaldehyde/l) than control $\left(21.33 \mathrm{~m} \mathrm{~mol} \mathrm{O}_{2} / \mathrm{kg}\right.$ and $4.31 \mathrm{mg}$ malonaldehyde/l). Results from the study indicate that both essential oil and aqueous extract of ginger can be utilized together as a source of natural antioxidant to inhibitive action on fish oil-in-water emulsion.
\end{abstract}

Keywords: Fish oil-in-water emulsion; Essential oil; Antioxidant assay; Oxidative stability; Ginger

\section{Introduction}

Fish oil is known to be a rich source of omega-3 ( $\omega-3$ or n-3) polyunsaturated fatty acids (PUFA), especially eicosapentaenoic acid (EPA) and docosahexaenoic acid (DHA). One of the major hurdles associated with delivery of oils high in PUFA into food is the susceptibility of these oils to oxidative deterioration. Lipid oxidation is a critical problem during food processing and storage as it decreases food quality and nutritive value. In general, antioxidants have been incorporated to prevent oxidative instability of food components and to prevent development of off-flavor compounds in food products [1]. The demand for novel natural antioxidants with potential antimicrobial, antifungal and antioxidant properties has been attracting more importance for incorporation in food products [2,3]. Nowadays, essential oils and their components are gaining increasing interest due to their potential multi-purpose functionality [4]. However, most of the essential oils have very low solubility in water due to their partial hydrophobic nature. One of the most acceptable solutions is to emulsify the essential oils in water in the form of tiny particles to form essential oil-in-water emulsion [5]. General intake of fish and fish products is inadequate, and it leads to the consumption of PUFA is less than the recommended intake [6]. To meet the recommended intake for these n-3 fatty acids especially EPA and DHA, efforts have been made to incorporate marine oils, rich in n-3 PUFA, into various food products [7]. However, the successful production of food products enriched with n-3 PUFA is impeded by their high susceptibility towards oxidative deterioration. Emulsion systems are being utilized for delivery of lipophilic health active compounds, such as polyunsaturated fatty acids, particularly EPA and DHA where they provide convenient and practical means for delivering these nutrients in human diets [8]. Essential oils and aqueous extracts of herbs and spices are gaining increasing importance due to their antioxidant and antimicrobial properties. Most of the emulsified foods products are in Oil-in-water emulsion nature [9]. Oil-in-water emulsion is more susceptible to lipid oxidation compared to bulk oil. Since, the oxidation of lipid usually takes place at interfacial surfaces incorporated antioxidant should reach such surfaces [10]. Although information is available on antioxidant capacity of several natural sources, studies on the effective way of introducing natural antioxidants into oil-in-water emulsion system are relatively few. In the present study, both essential oil (EO) and aqueous extract (AE) of ginger (Zingiber Officinale) rhizome were evaluated individually and their combination for effectiveness against lipid oxidation in fish oil-in-water emulsion system.

\section{Materials and Methods}

\section{Materials}

Butylated hydroxyl toluene (BHT), Folin-Ciocalteu's reagent, Catechol, Iron(III) chloride, Iron(II) chloride, 2-thiobarbituric acid (TBA), Tween 20, Methanol, 6-hydroxy-2,5,7,8- tetramethylchroman2-carboxylic acid (Trolox), linoleic acid and 2,4,6-tripyridyl-s-triazine (TPTZ) of analytical grade were used in the present study. Fish oil (Seacod, Universal Medicare, Mumbai, India) was used for emulsion preparation. The Ginger (Zingiber officinale) was purchased from local market and used as a source of natural antioxidants.

\section{Preparation of ginger aqueous extracts}

Fresh ginger rhizome was washed in tap water. $10 \mathrm{~g}$ of sample was ground by a blender with $100 \mathrm{ml}(10 \%)$ of distilled water for 1 minute. The ground mixture was filtered through a fine cotton cloth and the aqueous extracts (AE) was used for further analyses.

\section{Isolation of essential oil}

Essential oil (EO) of ginger (Zingiber officinale) rhizome was obtained by the method of $\mathrm{AOAC}[11]$ and stored at $4^{\circ} \mathrm{C}$ in inert

*Corresonding author: Jeya Kumari A, Scientist, Fish Processing Division, Central Institute of Fisheries Technology, 9 Cochin - 682029, Kerala, India Tel: +919605873642; E-mail: jeya131@gmail.com

Received October 20, 2014; Accepted November 20, 2014; Published January 07, 2015

Citation: Kumari AJ, Venkateshwarlu G, Choukse MK, Anandan R (2014) Effect of Essential Oil and Aqueous Extract of Ginger (Zingiber Officinale) on Oxidative Stability of Fish oil-in-Water Emulsion. J Food Process Technol 6: 412. doi: 10.4172/2157-7110.1000412

Copyright: $\odot 2014$ Kumari AJ, et al. This is an open-access article distributed under the terms of the Creative Commons Attribution License, which permits unrestricted use, distribution, and reproduction in any medium, provided the original author and source are credited. 
Citation: Kumari AJ, Venkateshwarlu G, Choukse MK, Anandan R (2014) Effect of Essential Oil and Aqueous Extract of Ginger (Zingiber Officinale) on Oxidative Stability of Fish oil-in-Water Emulsion. J Food Process Technol 6: 412. doi:10.4172/2157-7110.1000412

atmosphere until used. The yield percentages of essential oils are expressed in $\mathrm{ml} / 100 \mathrm{~g}$ ginger rhizome. The oil yield was in the range of $0.4-0.5 \%(\mathrm{v} / \mathrm{w})$. Essential oil was dissolved in methanol and their antioxidant activity was evaluated.

\section{Preparation of fish oil-in-water emulsions}

Five different fish oil-in-water emulsion formulations were prepared which includes i) $5 \%$ Fish oil ( $5 \mathrm{~g}$ fish oil $+95 \mathrm{~g}$ water ); ii) $5 \%$ Fish oil $+1 \%$ ginger essential oil $(5 \mathrm{~g}$ fish oil $+1 \mathrm{~g}$ ginger essential oil + $94 \mathrm{~g}$ water); iii) $5 \%$ Fish oil $+20 \%$ aqueous extract ( $5 \mathrm{~g}$ fish oil $+95 \mathrm{~g}$ of $20 \%$ ginger aqueous extract); iv) $5 \%$ Fish oil $+1 \%$ ginger essential oil + $20 \%$ aqueous extract ( $5 \mathrm{~g}$ fish oil $+1 \mathrm{~g}$ ginger essential oil $+95 \mathrm{~g}$ of $20 \%$ ginger aqueous extract); v) 5\% Fish oil $+0.01 \% 105$ BHT (5 g fish oil $+0.01 \mathrm{~g} \mathrm{BHT}+94.99 \mathrm{~g}$ water$)$. Tween 20 (10\% of total oil) was used as an emulsifier. Emulsification was carried out by using homogenizer (Poly system PT 2100, Kinematica, AG) at 25,000 rpm for 2 minutes. Samples were placed in eppendrof tubes $(2 \mathrm{ml})$, closed and kept under refrigerated conditions $\left(4^{\circ} \mathrm{C}\right)$. Oxidative stability of samples was analyzed at known intervals $(1,3,5 \ldots \ldots 21$ days) up to 21 days.

\section{Determination of antioxidant property}

2, 2-Diphenyl-1-picrylhydrazyl (DPPH) radical scavenging method: The antioxidant activity of ginger essential oil and extract was measured by DPPH (2, 2-Diphenyl-1-picrylhydrazyl) radical scavenging assay according to the method followed by Brand-Williams et al. [12]. A volume of $50 \mu \mathrm{l}$ of a methanolic stock solution of essential oils of four different concentrations $(5,10,20$ and $50 \mathrm{~g} / \mathrm{l})$ was kept in a screw cap test tube and $2 \mathrm{ml}$ of $6 \times 10^{-5} \mathrm{M}$ methanolic solution of DPPH was added. The mixtures were well shaken and then placed in a dark room. The decrease in absorbance at $517 \mathrm{~nm}$ was determined using a UV- spectrophotometer (Thermo spectronic, UK, Model UV 1) after $30 \mathrm{~min}$ for all the samples. Methanol was used to zero the spectrophotometer. Absorbance of the radical without antioxidant (control) was measured daily. Inhibition (\%) was plotted against the sample concentration. The percentage inhibition of the DPPH radical was calculated according to the formula of Yen and Duh [13]

$$
\mathrm{I}=[(\mathrm{AB}-\mathrm{AS}) / \mathrm{AB}] \times 100
$$

Where, $\mathrm{I}=\mathrm{DPPH}$ inhibition (\%), $\mathrm{AB}=$ absorbance of control sample $(0 \mathrm{~min})$ and $\mathrm{AS}=$ absorbance of a tested sample at the end of the reaction (after $30 \mathrm{~min}$ ).

\section{Determination of Total phenol content (TPC)}

The total phenol content was determined by the method of Singleton and Rossi [14]. A known volume of methanolic solution of essential oils/extracts was introduced into test tubes followed by $2.5 \mathrm{ml}$ Folin-Ciocalteu's reagent (diluted 10 times with water) and $2 \mathrm{ml}$ sodium carbonate $(7.5 \% \mathrm{w} / \mathrm{v})$. The tubes were vortexed, and incubated at $50^{\circ} \mathrm{C}$ for $5 \mathrm{~min}$. Absorption at $760 \mathrm{~nm}$ was measured with a UV-spectrophotometer. A standard curve was prepared for different concentrations of the working standard. The content of phenols in the test samples were found out from the standard curve and the results were expressed as $\mathrm{mg}$ catechol equivalents/L sample.

\section{Ferric reducing antioxidant power (FRAP) assay}

The FRAP (Ferric Reducing Antioxidant Power) assay was carried out according to the procedure of Benzie and Strain [15] with some modifications. The FRAP reagent was prepared fresh daily and was warmed to $37^{\circ} \mathrm{C}$ in a water bath prior to use. $50 \mu$ of sample was added to $1.5 \mathrm{ml}$ of the FRAP reagent. The absorbance of the reaction mixture was then recorded at $593 \mathrm{~nm}$ after $4 \mathrm{~min}$. The standard curve was constructed using iron (II) sulphate solution (100-2000 $\mu \mathrm{M})$, and the results were expressed as $\mu \mathrm{mol} \mathrm{Fe}$ (II)/g extract/oil.

\section{Ferric reducing antioxidant power (FRAP) assay}

The FRAP (Ferric Reducing Antioxidant Power) assay was carried out according to the procedure of Benzie and Strain [15] with some modifications. The FRAP reagent was prepared fresh daily and was warmed to $37^{\circ} \mathrm{C}$ in a water bath prior to use. $50 \mu \mathrm{l}$ of sample was added to $1.5 \mathrm{ml}$ of the FRAP reagent. The absorbance of the reaction mixture was then recorded at $593 \mathrm{~nm}$ after $4 \mathrm{~min}$. The standard curve was constructed using iron (II) sulphate solution (100-2000 $\mu \mathrm{M})$, and the results were expressed as $\mu \mathrm{mol} \mathrm{Fe} \mathrm{(II)/g} \mathrm{extract/oil.}$

\section{$\beta$-carotene bleaching assay}

The antioxidant activity based on coupled oxidation of $\beta$-carotene and linoleic acid emulsion system was evaluated by the method described by Taga et al. [16]. $2 \mathrm{mg}$ of $\beta$ carotene was dissolved in 20 $\mathrm{ml}$ chloroform and $3 \mathrm{ml}$ aliquot of this solution was taken in a 250 $\mathrm{ml}$ round bottom flask and $40 \mathrm{mg}$ linoleic acid and $400 \mathrm{mg}$ Tween 20 were added. Chloroform was removed from the solution by a rotary evaporator. $100 \mathrm{ml}$ of oxygenated distilled water was added into the $\beta$ carotene emulsion and mixed well. $3 \mathrm{ml}$ of aliquot of this emulsion was added to $50 \mu \mathrm{l}$ of the sample in a capped culture tube and mixed thoroughly. The tubes were immediately placed in a water bath and incubated at $50^{\circ} \mathrm{C}$. Oxidation of beta carotene was monitored spectrophotometrically by measuring the absorbance at $470 \mathrm{~nm}$. A control was prepared using $50 \mu \mathrm{l}$ of distilled water instead of sample. Antioxidant activity was expressed as percentage inhibition relative to control using the following equation. The antioxidant activity was expressed as inhibition percentage with reference to the control after a $60 \mathrm{~min}$ incubation using the following equation:

$$
\mathrm{AA}(\%)=100(\mathrm{DRC}-\mathrm{DRS}) / \mathrm{DRC}
$$

Where, $\mathrm{AA}=$ antioxidant activity; $\mathrm{DRC}=$ degradation rate of the control $=[\ln (\mathrm{a} / \mathrm{b}) / 60] ;$ DRS $=$ degradation rate in presence of the sample $=[\ln (\mathrm{a} / \mathrm{b}) / 60] ; \mathrm{a}=$ absorbance at time $0 \mathrm{~min} ; \mathrm{b}=$ absorbance at $60 \mathrm{~min}$.

\section{Chemical composition analysis of essential oil by gas chromatography and mass spectrophotometer (GC-MS)}

Chemical composition of essential oil was performed using Gas Chromatography Mass Spectrometer (GC-MS) (Shimadzu, QP2010) instrument equipped with a Carbowax $(30 \mathrm{~m} \times 0.25 \mathrm{~mm}$ ID; 0.25 $\mu \mathrm{m}$ film thicknesses) capillary column (Cromlab S. A.). For GC-MS detection, an electron ionization system with ionization energy of 70 $\mathrm{eV}$ was used. Helium gas was used as the carrier gas at a constant flow rate of $1 \mathrm{ml} / \mathrm{min}$. Injector and MS transfer line temperature were set at $250^{\circ} \mathrm{C}$. Diluted samples $(1 / 100, \mathrm{v} / \mathrm{v}$, in Heptane) of $1.0 \mu \mathrm{l} / \mathrm{min}$ were injected manually in the split mode (1:15). The column temperature was programmed initially at $40^{\circ} \mathrm{C}$ for $4 \mathrm{~min}$ and then to increase at a rate of $4^{\circ} \mathrm{C}$ per min to a final temperature of $240^{\circ} \mathrm{C}$. Total run time was $54 \mathrm{~min}$.

\section{Determination of oxidative stability}

Peroxide values of emulsions were determined according to the method described by Shantha and Decker [17]. $0.3 \mathrm{ml}$ of sample was mixed with $1.5 \mathrm{ml}$ of isooctane/2-propanol $(3: 1, \mathrm{v} / \mathrm{v})$ then, the organic phase was separated by centrifugation at $10,000 \mathrm{rpm}$ for $2 \mathrm{~min}$. The organic solvent phase $(0.2 \mathrm{ml})$ was added to $2.8 \mathrm{ml}$ of methanol/1- 
butanol $(2: 1, \mathrm{v} / \mathrm{v})$. To the above mixture $30 \mu \mathrm{l}$ of ammonium thiocynate and ferrous solution mixture was added and mixed well. The sample mixture was allowed to react exactly for $20 \mathrm{~min}$. The absorbance was measured at the wavelength of $510 \mathrm{~nm}$ using spectrophotometer. Hyperperoxide concentration in the sample was determined using a standard curve made from cumene hyroperoxide and expressed in millimol of oxygen/L emulsion. Changes in secondary oxidation products of the emulsion were determined by measuring TBARS (Thiobarbituric acid reactive substances) value according to the method described by McDonald and Hultin [18]. $2 \mathrm{ml}$ of TBA (Thiobarbituric acid) reagent was taken in test tube and $1 \mathrm{ml}$ of sample was added. The blank was prepared with $1 \mathrm{ml}$ of distilled water instead of sample. Test tubes were closed and mixed thoroughly by vortexing twice and incubated in a boiling water bath $\left(100^{\circ} \mathrm{C}\right)$ for $15 \mathrm{~min}$ and then cooled by placing in a cool water bath for $10 \mathrm{~min}$. Further, the sample mixture was centrifuged at $1000 \mathrm{rpm}$ for $15 \mathrm{~min}$. The absorbance of the supernatant was measured at $532 \mathrm{~nm}$. TBARS was expressed in $\mathrm{mg}$ of malanoldehyde $/ \mathrm{kg}$. TBARS were expressed in $\mathrm{mg}$ of malonaldehyde/L emulsion.

\section{Statistical analysis}

The data obtained were analyzed by running one way analysis of variance (ANOVA) using SPSS software version 16.0 (SPSS Inc, Chicago, Illinois, USA). A one way ANOVA was used to evaluate difference in the mean value (PV and TBARS) of samples and control. All mean separations were carried out by Duncan multiple range test using the significance level of $95 \%(\mathrm{p}<0.05)$.

\section{Results and Discussion}

\section{Antioxidant activity of essential oil and aqueous extract of ginger}

The use of simplified antioxidant assays for quantifying the antioxidant action can be very helpful in clarifying the action of potential antioxidants [9]. The results of a single-assay can give only a reductive suggestion of the antioxidant properties. Therefore, an approach with multiple assays in screening work is highly advisable [19]. In the present study, antioxidant activity of essential oil and aqueous extract of ginger was evaluated by four different antioxidant assays such as DPPH, FRAP, Folin-Ciocalteu, and $\beta$-carotene bleaching methods. Antioxidant activity of essential oil and aqueous extract of ginger was tested at different concentration level $(0.5-20 \%$ for aqueous extracts, $0.5-5 \%$ for essential oil). Results of antioxidant activity of $\mathrm{EO}$ and $\mathrm{AE}$ of ginger rhizome are given in Table 1. The DPPH radical-scavenging activities indicated that antioxidant activity was high $(78.68 \%)$ at $5 \%$ concentration of essential oil and also high $(89.72 \%)$ at $20 \%$ of aqueous extract. Manuel et al. [20] observed similar results of antioxidant activity of essential oils at higher concentration. The total phenolic content could be used as an important indicator of the antioxidant capacity, which may be used as a preliminary screen for essential oils for use as natural sources of antioxidants in functional foods [21]. Ginger essential oil showed high phenolic content [130.70 mg Catechol equivalents $/ 1$ ] at $5 \%$ level of concentration than aqueous extract [ 97.69 $\mathrm{mg}$ Catechol equivalents $/ 1$ ] at $20 \%$ concentration. Baris et al. [22] also found similar results and reported that weaker anti oxidative capacity of the extract could be attributed to the presence of polar phenolics as they were found in the extract at low concentration. In the present study, a concentration dependent ferric reducing antioxidant power (FRAP) of essential oils was observed with the highest activity of 190.52 $\mu \mathrm{mol} \mathrm{Fe}(\mathrm{II}) / \mathrm{g}$ ) at $5 \%$ concentration. Similarly, the FRAP of ginger extract showed highest activity of $107.59 \mu \mathrm{mol} F e(I I) / g$ dry wt in $20 \%$ concentration. $\beta$-carotene bleaching method is based on the loss of the yellow colour of $\beta$-carotene due to its reaction with radicals which are formed by linoleic acid oxidation in an emulsion [23]. This fact is used in the antioxidant activity evaluation of essential oil and extracts of ginger. Antioxidant activity determined by $\beta$-carotene bleaching assay revealed that ginger essential oil had an antioxidant activity of $52.94 \%$ at $5 \%$ concentration and aqueous extracts had an antioxidant activity of $54.85 \%$ at $20 \%$ concentration. Results from the study agreement with similar results observed for oregano essential oil [24]. In comparison, the essential oil showed relatively significant $(\mathrm{p}<0.05)$ antioxidant effect than aqueous extracts at lower concentration. The antiradical efficiency of an effective antioxidant is measured in terms of its ability to counteract the higher levels of reactive radicals even at lower concentration [25].

\section{Chemical composition of ginger essential oil}

Chemical composition of Ginger (Zingiber officinale) essential oil was determined by GC-MS analyses showed Ginger essential oil contained, zingiberene $(27.45 \pm 0.30 \%)$, copaene $(13.82 \pm 0.06 \%)$, camphane $(11.10 \pm 0.16 \%)$ and geranial $(10.98 \pm 0.10)$ as major compounds Table 2 . Results from this study are agreement with similar studies done for the chemical composition of ginger essential oil [2628]. Though copaene was not reported in the previous report, it was the second major component found $(13.81 \pm 0.06 \%)$ in the present study.

\section{Changes in lipid peroxide value of fish oil-in-water emulsion}

Oxidation of lipids is one of the basic processes causing rancidity in food products [29]. The mechanism for lipid oxidation in oil-inwater emulsions differs from bulk lipids because emulsions have an aqueous phase which contains both pro oxidants and antioxidants and oil-in water interface that impact interactions between oil and water components. The selection of suitable antioxidant is of great importance to inhibit lipid oxidation in different food systems. In the present study, antioxidant effectiveness in the model systems of fish oil-in-water emulsion prepared with essential oil and aqueous extract and their oxidative stability was evaluated up to 21 days. Highest concentrations of ginger aqueous extract $(20 \%)$ was used for evaluating their efficacy in exercising the oxidative stability in an emulsion system and $1 \%$ concentration of ginger essential oil was used based on emulsion stability. Hydro peroxides were measured to determine the initial rate of oxidation because they are generally accepted as the first product formed by oxidation [30]. Peroxides are the primary products of lipid oxidation and play a central role in auto oxidation of lipids and decomposed into carbonyls and other compounds. The rate of lipid oxidation increases as the droplet size decreases, because of the increased surface area that is exposed to the aqueous phase. The level of per oxidation was lower $\left(12.62 \mathrm{mmolO}_{2} /\right.$ $\mathrm{kg})$ in the fish oil-in-water emulsion prepared with EO (1\%). In case of emulsion prepared with $20 \% \mathrm{AE}$, it was $13.42 \mathrm{mmolO}_{2} / \mathrm{kg}$ on $21 \mathrm{st}$ day Figure 1. Combination of EO (1\%) and AE (20\%), significantly $(\mathrm{p}<0.05)$ counteracted the per oxidation $\left(3.91 \mathrm{mmolO}_{2} / \mathrm{kg}\right.$ on 21 st day $)$ in the fish oil-in-water emulsion. Sajid and Benjakul [31] observed higher PV in the control sample than the samples added with phenolic compounds in menhaden oil-in-water emulsion. Further, It has been reported that gingerol, shogaol, curcumin and diarylheptanoids are the major compounds present in the ginger rhizome work as antioxidant, anti-inflammatory, anti-lipid, anti-diabetic, analgesic, antipyretic and anti-tumor [32,33]. The peroxide value of control was $21.33 \mathrm{mmolO}_{2} /$ $\mathrm{kg}$ which was significantly $(\mathrm{p}<0.05)$ higher than the other samples containing essential oil/aqueous extracts of ginger. The results indicated the combined effect of ginger essential oil and aqueous extract which 
Citation: Kumari AJ, Venkateshwarlu G, Choukse MK, Anandan R (2014) Effect of Essential Oil and Aqueous Extract of Ginger (Zingiber Officinale) on Oxidative Stability of Fish oil-in-Water Emulsion. J Food Process Technol 6: 412. doi:10.4172/2157-7110.1000412

Page 4 of 5

\begin{tabular}{|c|c|c|c|c|}
\hline Sample Concentration (\%) & $\%$ DPPH inhibition & FRAP (miromol Fe(II) /g dry wt) & $\begin{array}{c}\text { Total phenolics mg Catechol } \\
\text { equivalents/l }\end{array}$ & $\begin{array}{c}\beta-\text { carotene bleaching assay ( } \% \\
\text { Anti-Oxidant Activity) }\end{array}$ \\
\hline \multicolumn{5}{|l|}{ Essential oil } \\
\hline 0.5 & $32.74 \pm 0.02^{\mathrm{a}}$ & $82.25 \pm 0.05^{a}$ & $29.49 \pm 0.15^{\mathrm{a}}$ & $26.36 \pm 0.07^{a}$ \\
\hline 1 & $52.03 \pm 0.04^{b}$ & $123.42 \pm 0.04^{b}$ & $58.89 \pm 0.08^{b}$ & $33.04 \pm 0.15^{b}$ \\
\hline 2 & $74.81 \pm 0.05^{c}$ & $167.35 \pm 0.07^{c}$ & $106.6 \pm 0.20^{c}$ & $44.43 \pm 0.06^{c}$ \\
\hline 5 & $78.68 \pm 0.04^{d}$ & $190.52 \pm 0.12^{d}$ & $130.70 \pm 0.04^{d}$ & $52.94 \pm 0.22^{d}$ \\
\hline \multicolumn{5}{|l|}{ Aqueous extract } \\
\hline 0.5 & $5.92 \pm 0.02^{\mathrm{a}}$ & $24.75 \pm 0.04^{a}$ & ND & $12.57 \pm 0.52^{a}$ \\
\hline 1 & $9.24 \pm 0.01^{b}$ & $32.59 \pm 0.02^{\mathrm{b}}$ & ND & $13.48 \pm 0.45^{\mathrm{b}}$ \\
\hline 2 & $13.27 \pm 0.01^{c}$ & $35.42 \pm 0.02^{c}$ & ND & $24.52 \pm 0.45^{c}$ \\
\hline 5 & $35.31 \pm 0.03^{d}$ & $49.65 \pm 0.05^{d}$ & $24.38 \pm 1.25^{a}$ & $41.52 \pm 0.34^{d}$ \\
\hline 10 & $76.29 \pm 0.05^{\mathrm{e}}$ & $98.42 \pm 0.06^{e}$ & $63.95 \pm 0.04^{b}$ & $47.15 \pm 0.17^{e}$ \\
\hline 20 & $89.72 \pm 0.07^{f}$ & $107.59 \pm 0.05^{f}$ & $97.69 \pm 0.01^{c}$ & $54.85 \pm 0.05^{f}$ \\
\hline
\end{tabular}

Where,

DPPH-2, 2- Diphenyl-1-picrylhydrazyl (DPPH) radical scavenging assay;

FRAP- Ferric Reducing Antioxidant Power assay;

Results are mean $\pm S D, n=3$; Values within a column with different superscript letters are significantly $(p<0.05)$ different. ND $=$ Not detected.

Table 1: Antioxidant activity of essential oil and aqueous extracts of ginger rhizome

\begin{tabular}{|c|c|c|}
\hline SI. No. & Compound & Peak area (\%) \\
\hline \multicolumn{3}{|c|}{ Monoterpenoids } \\
\hline 1 & $\alpha$-pinene & $3.20 \pm 0.14$ \\
\hline 2 & Camphene & $11.10 \pm 0.16$ \\
\hline 3 & $\beta$-pinene & $1.84 \pm 0.02$ \\
\hline 4 & Limonene & $1.82 \pm 0.04$ \\
\hline 5 & $\beta$-Phellandrene & $6.21 \pm 0.05$ \\
\hline 6 & Cineole & $3.53 \pm 0.04$ \\
\hline 7 & Linalool & $0.39 \pm 0.01$ \\
\hline 8 & a-myrcene & $0.20 \pm 0.01$ \\
\hline 9 & $(+)$ - $\beta$-citronellol & $0.43 \pm 0.02$ \\
\hline 10 & Citral & $5.94 \pm 0.08$ \\
\hline 11 & a-terpineol & $0.61 \pm 0.01$ \\
\hline 12 & Geranial & $10.98 \pm 0.10$ \\
\hline \multirow[t]{2}{*}{13} & Geranyl acetate & $0.95 \pm 0.13$ \\
\hline & Total & 47.72 \\
\hline \multicolumn{3}{|c|}{ Sesquiterpenoids } \\
\hline 1 & Germacrene-A & $0.65 \pm 0.02$ \\
\hline 2 & Zingiberene & $27.45 \pm 0.30$ \\
\hline 3 & a-farnesene & $6.58 \pm 0.05$ \\
\hline 4 & Copaene & $13.82 \pm 0.06$ \\
\hline \multirow[t]{2}{*}{5} & Nerolidol & $0.32 \pm 0.02$ \\
\hline & Total & 48.82 \\
\hline
\end{tabular}

Table 2: Chemical composition of ginger essential oil (Zingiber officinale)

are comparable to the results of BHT $\left(3.65 \mathrm{mmolO}_{2} / \mathrm{kg}\right.$ at $21 \mathrm{st}$ day) in the fish oil-in-water emulsion. Lipid oxidation is accelerated by reactions that take place at the surface of $\mathrm{o} / \mathrm{w}$ emulsion droplets. The rate of lipid oxidation increases as the droplet size decreases, because of the increased surface area that is exposed to the aqueous phase [10].

\section{Changes in TBARS value of fish oil-in-water emulsion}

The extent of lipid oxidation in fish oil-in-water emulsion prepared with $1.0 \%$ ginger essential oil was $3.94 \mathrm{mg}$ malonaldehyde $/ \mathrm{l}$ emulsion by day 21 Figure 2 . Similarly, emulsion prepared with $20 \%$ aqueous ginger extract was $4.34 \mathrm{mg}$ malonaldehyde /l emulsion by day 21 . During the storage period of 21 days, TBARS value in control sample was significantly $(\mathrm{p}<0.05)$ higher $(5.08 \mathrm{mg}$ malonaldehyde $/ \mathrm{l}$ emulsion $)$ than the fish oil-in-water emulsion with essential oil/aqueous extracts of ginger. The activities of essential oils such as antioxidants depend not only on their structural features but also on many other factors, such as concentration, temperature, light, type of substrate and physical state of the system, as well as on micro components acting as prooxidants or synergists [30]. It is noticed that the antioxidant potential of ginger essential oil is more effective in counteracting the lipid oxidation process in fish oil in water emulsion as compared to ginger aqueous extract. Further, the level of malonaldehyde was less $(3.25 \mathrm{mg}$ malonaldehyde $/ 1$ emulsion) in fish oil-in-water emulsion prepared with $1.0 \% \mathrm{EO}$ and $20 \% \mathrm{AE}$ and it was comparable to BHT $(2.43 \mathrm{mg}$ malonaldehyde /1 emulsion), Isabel et al. [34] also observed similar

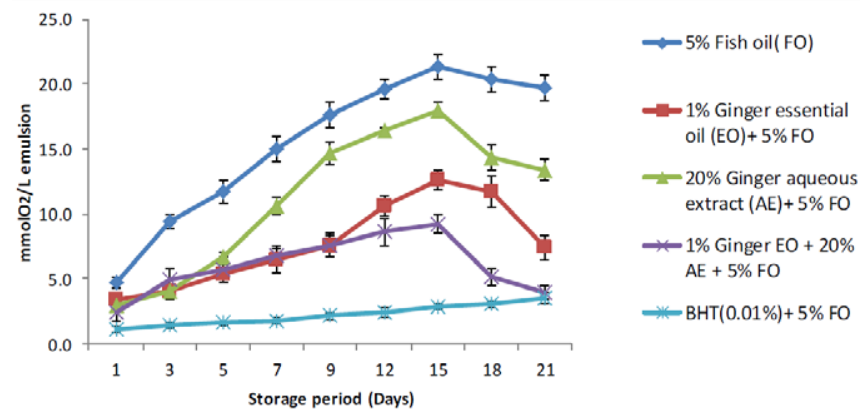

Figure 1: Peroxide Value (PV): Effect of Essential Oil and Aqueous Extracts of Ginger an Lipid Oxidation af Fish Oil-In-Water Emulsion

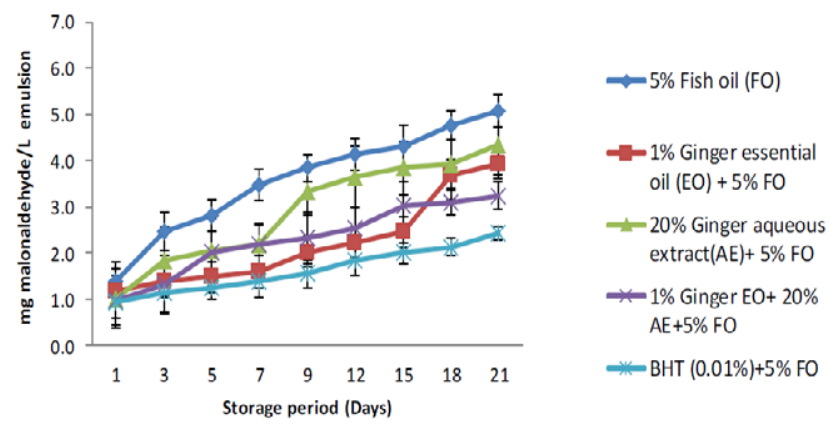

Figure 2: Thiobarbituric Acid Reactive Substances (TBARS): Effect of Essential Oil and Aqueous Extracts of Ginger on Lipid Oxidation of Fish Oil-in-water emulsion 
Citation: Kumari AJ, Venkateshwarlu G, Choukse MK, Anandan R (2014) Effect of Essential Oil and Aqueous Extract of Ginger (Zingiber Officinale) on Oxidative Stability of Fish oil-in-Water Emulsion. J Food Process Technol 6: 412. doi:10.4172/2157-7110.1000412

results and reported that significant lipid oxidation reduction in fish oil-in-water emulsions with addition of rosemary extracts. Jang-Hyuk et al. [35] reported that mixture of natural plant extract showed better antioxidant activity in micro encapsulated sunflower oil. Results from the study indicate that the potential of using ginger essential oil and its aqueous extract in combination as natural antioxidant substances in the preparation of fish oil-in-water emulsion formulations.

\section{Conclusion}

The overall objective of the present study was to evaluate the stability of oil-in-water emulsions containing omega-3 fatty acids with the addition of essential oil and aqueous extract of ginger rhizome. Anti-oxidative activities of essential oil and aqueous extract of ginger rhizome tested by four different test systems (2, 2-Diphenyl-1picrylhydrazyl, Ferric reducing antioxidant power, Folin-Ciocalteu's reagent and $\beta$-carotene bleaching) revealed that essential oil has more anti oxidative activity potential than aqueous extract. In oil-in-water emulsions, the essential oil acted more efficiently against lipid oxidation compared to aqueous extract. Further, ginger essential oil and aqueous extract together showed comparable results with synthetic antioxidant like BHT as observed by PV and TBARS values. In conclusion, both essential oil and aqueous extract of ginger can be utilized together as a source of natural antioxidant to improve their inhibitive action on both sides of the oil-water interface. Further, it can be used to deliver fish oils in an emulsion form that allows incorporation of sensitive functional ingredients into food without affecting the taste, aroma, or texture.

\section{Acknowledgements}

Authors thank Director, Dr. W. S. Lakra, Central Institute of Fisheries Education, Mumbai for providing the required facilities. First author acknowledges Indian Council of Agricultural Research (ICAR), New Delhi for awarding senior research fellowship to carry out Ph.D programme.

\section{References}

1. Yu L, Scanlin L, Wilson J, Schmidt G (2002) Rosemary extracts as inhibitors of lipid oxidation and color change in cooked turkey products during refrigerated storage. J Food Sci 67: 582-585.

2. Aligiannis N, Mitaku S, Tsitsa-Tsardis E, Harvala C, Tsaknis I, et al. (2003) Methanolic extract of Verhascum macrurum as a source of natural preservative against oxidative rancidity. J Agric Food Chem 51: 7308-7312.

3. Athukorala Y, Lee K, Shahidi F, Heu MS, Kim H, et al. (2003) Antioxidant efficacy of extracts of an edible red algae (Grateloupia filicina) in linoleic acid and fish oil. J Food Lipids 10: 313-327.

4. Ormancey X, Sisalli S, Coutiere $P$ (2001) Formulation of essential oils in functional perfumery. Parfums Cosmetiques Actualites 157: 30-40.

5. Edris AE (1998) Preparation and stability of a protein stabilized orange oil-inwateremulsion". Nahrung 42: 19-22.

6. World Health Organisation (WHO) (2003) Diet, nutrition and the prevention of chronic diseases. Technical Report Series, Geneva, 916.

7. Trautwein EA (2001) n-3 fatty acids-physiological and technical aspects for their use in food. Eur J Lipid Sci Technol 103: 45-55.

8. Augustin MA, Sanguansri L (2003) Polyunsaturated fatty acids; delivery, innovation and incorporation on to foods. Food Aus 55: 294-296.

9. Frankel EN, Satue-Gracia T, Meyer AS, German JB (2002) Oxidative stability of fish and algal oils containing long chain polyunsaturated fatty acids in bulk and in oil-in-water emulsions. J Agric Food Chem 50: 2094-2099.

10. Mc Clements DJ, Decker EA (2000) Lipid oxidation in oil-in water emulsions: impact of 330 molecular environment on chemical reactions in heterogeneous food systems. J Food Sci 331 65: 1270-1282.

11. AOAC (1980) Official methods of analysis, (13thedn). Association of Official Analytical Chemists, Washington DC 334.
12. Brand-Williams, Cuvelier ME, Berset C (1995) Use of a free radical method to evaluate antioxidant activity. LWT-Food Sci Technol 28: 25-30.

13. Yen GC, Duh PD (1994) Scavenging effect methanolic extracts of peanut hulls on free-radical and active oxygen species. J Agric Food Chem 42: 629-632.

14. Singleton VL, Rossi JA (1965) Colorimetry of total phenolics with phosphomolybdicphosphotungstic acid reagents. Am J Enol Viticult 16: 144-158.

15. Benzie IF, Strain JJ (1997) The ferric reducing ability of plasma (FRAP) as a measure of "antioxidant power": The FRAP assay. Anal Biochem 239: 70-76.

16. Taga MS, Miller E, Prat DE (1984) Chia seeds as a source of natural lipid antioxidant. J Am Oil Chem Soc 61: 928-931.

17. Shantha NC, Decker EA (1994) Rapid, sensitive, iron-based spectrophotometric methods for determination of peroxide values of food lipids. J AOAC Int 77 421-424.

18. Mcdonald RE, Hultin HO (1987) Some characteristics of the enzymatic lipid peroxidation system in the microsomal fraction of flounder skeletal muscle. J Food Sci 52: 15-21.

19. Sacchetti G, Maietti S, Muzzoli M, Scaglianti M, Manfredini S, et al. (2005) Comparative evaluation of 11 essential oils of different origin as functional antioxidants,antiradicals and antimicrobials in foods. Food Chem 91: 621-632.

20. Manuel VM, Yolanda RN, Elena SZ, Juana FL, Jose AP (2010) Antioxidant activity of essential oils of five spice plants widely used in a Mediterranean diet. Flavour and Fragr J 25: 13-19.

21. Liu H, Qiu N, Ding H, Yao R (2008) Polyphenols contents and antioxidant capacity of 68 Chinese herbals suitable for medical or food uses. Food Res Int 41: 363-370.

22. Baris O, Gullce M, Sahin F, Ozer H, Klic H, et al. (2006) Biological Activities of the Essential Oil and Methanol Extract of Achillea biebersteinii Afan. (Asteraceae). Turk J Biol 30: 65-73.

23. Kumazawa S, Taniguchi M, Suzuki Y, Shimura M, Kwon M, et al. (2002) Antioxidant activity of polyphenols in carob pods. J Agric Food Chem 50: 373-377.

24. Kulisica T, Radonicb A, Katalinicc V, Milos M (2004) Use of different methods for testing antioxidative activity of oregano essential oil. Food Chem 85: 633-640.

25. Sanchez-Moreno C, Larrauri JA, Saura-Calixto FA (1998) Procedure to measure the antiradical efficiency of polyphenols. J Sci Food Agric 76: 270-276.

26. Singh G, Maurya S, Catalan C, deLampasona MP (2005) Studies on essential oils, part 42: Chemical, antifungal, antioxidant and sprout suppressant studies on ginger essential oil and its oleoresin. Flavour Frag J 20: 1-6.

27. Wohlmuth H, Smith MK, Brooks LO, Myers SP, Leach D (2006) Essentia oil composition of diploid and tetraploid clones of ginger (Zingiber officinale Roscoe) grown in Australia. J Agric Food Chem 54: 1414-1419.

28. Norajit K, Laohakunjit N, Kerdchoechuen O (2007) Antibacterial effect of five Zingiberaceae essential oils. Molecules 12: 2047-2060.

29. Laguerre M, Lecomte J, Villeneuve $P$ (2007) Evaluation of the ability of antioxidants to counteract lipid oxidation: existing methods, new trends and challenges. Prog Lipid Res 46: 244-282.

30. Yanishlieva- Maslarova NV (2001) Inhibiting oxidation. In Antioxidants in Food: Practical Applications; J. Pokorny, N. Yanishlieva, M. Gordon, Eds.; CRC Press, Woodhead Publishing Limited, Cambridge, pp 22-70.

31. Sajid M, Benjakul S (2010) Comparative studies of four different phenolic compounds on in vitro antioxidative activity and the preventive effect on lipid oxidation of fish oil emulsion and fish mince. Food Chem 119: 123-132.

32. Sasidharan I, Nirmala Menon A (2010) Comparative Chemical Composition and Antimicrobial Activity Fresh \& Dry Ginger Oils (Zigiber Officinale Roscoe). Int J Current Pharma Res 2: 40-43.

33. Hsiang-yu Y, Cheng-hung C, Hsin-chun C, Chu-jen W, Tai-liang C, et al. (2013) Bioactive components analysis of two various gingers (Zingiber officinale Roscoe) and antioxidant effect of ginger extracts. LWT-Food Science and Technology 55: 329-334.

34. Isabel M, Jesus Gonzalez M, Manuel P, Dorotea DM, Raffaele S, et al. (2003) Activity of plant extracts for preserving functional food containing $n$-3-PUFA Eur Food Res and Tech 217: 301-307.

35. Jang-Hyuk A, Young-Pil K, Eun-Mi S, Young-Ki C, Hak-Sung K (2008) Antioxidant effect of natural plant extracts on the microencapsulated high oleic sunflower oil. J Food Engg 84: 327-334. 